\title{
Prevalence of Aneamia and Malnutrition among Gaddi Girls of Chamba and Kangra District of Himachal Pradesh
}

\author{
Shubhangna Sharma, Rita Rani and Meenakshi Samkaria \\ Department of Human Development, COHS, CSK, HPKV, Palampur 176062 , \\ Himachal Pradesh, India \\ E-mail: Ritarani1234@rediff mail.com
}

KEYWORDS Health profile; malnutrition; tribal women; aneamia; body mass index

ABSTRACT The present study was undertaken with the objective to find out the health profile including aneamia and body mass index of adolescent Gaddi girls. A total of 400 adolescent Gaddi girls in the age group of 11-18 year had been selected (200 males and 200 females) from each district (Chamba and Kangra). The heamoglobin level was checked with the help of Sahli's apparatus. The results indicate that most of the girls were suffering from severe cases of aneamia and malnutrition of chronic energy deficiency grade III. No single girls had normal haemoglobin level. This was due to inadequate intake of all necessary food groups, unbalanced diet and heavy work load.

\section{INTRODUCTION}

Gaddis are one of the famous tribe of Himachal Pradesh. They are semi-nomadic herdsmen or shepherd, semi-agricultural and semi-pastoral tribe. They have migrate to plains during winter in search of fodder for their live stock.

Women and girls of Gaddis play important role in household activities as they do household chores and field work. In this tribe girls get married in adolescent age (Mohan, 2002).

Generally, in tribes most of the girls get married in their adolescence and have had two or three children before they reach their twentieth birthday and as a result they are overburdened with additional household responsibilities at the age when they are not prepared for it, Young girls are often neglected in feeding and health care practices. Unequal distribution of food in the family with definite discrimination against girl child has been observed in India but this discrimination is more in poorer society and tribes (Gupta and Monica, 1987).

However, data on height and weight of Indian girls showed that many of them do not achieve their growth potential remain stunted or wasted due to malnutrition. Malnutrition also lead to aneamia.

Adolescent girls are future homemakers; their attainment and competenence will be determining the health and nutrition of children of our next generation it is the adolescent segment of our population, which has neglected, in our entire developmental and educational plan. It is therefore becomes necessary to look at adolescent girls in age group of $11-18$ years

With this rationale, the following objectives was to determine the prevalence of anaemia and nutritional status among Gaddi girls.

\section{MATERIAL AND METHOD}

The study was carried out in Kangra and Chamba district of Himachal Pradesh.

Selection of Subjects: Out of 12 district of Himachal Pradesh, two district were selected viz Kangra and Chamba since maximum gaddi tribe are residing in these two district only. Ten village from each district thus making the total sample size of 400 adolescent girls. Girls from mobile tribes, small marginal and upper socio- economic class have been drawn through random sampling technique. Ten village from each district were selected where the density of population of gaddi tribes was higher. After the collection of data the information gathered was tabulated. The statistical tools applied were per cent ages and chi-square test.

Tool: The data were collected with the help of interview schedule and personal observations which comprise of 1. Body Mass Index and 2. Haemoglobin Level

Body Mass Index: BMI is an indicator of relative fatness (adiposity). It can be calculated as

BMI $=$ Weight $/$ Height $^{2}$ 
Arbitrarily classified individual with BMI in the ranges 25.0-30.0 grade I obese, those in the range of above 30.0 as grade II obese, those in range of 20.0-25.0 considered as normal, individual with BMI below 16.0 considered as chronic energy deficiency grade III,16.0-17.0 as chronic energy deficiency grade II, 17.0-18.5 as chronic energy deficiency grade I, 18.5-20.0 as low weight but normal.

Determination of Haemoglobin: A sample of $0.02 \mathrm{ml}$ of blood was sucked in a pipette and then transferred into the tube containing $2 \mathrm{ml}$ of N/10 hydrochloric acid and allowed to stand for about $5 \mathrm{~min}$. It was then diluted drop by drop with distilled water till the colour matched with that of standard (Sahli's apparatus a kit containing heamometer, pipette, heamometer tube, $\mathrm{N} / 10 \mathrm{HCl}$ and dropper). The total amount was proportionate to the concentration of haemoglobin in the blood and reading was noted down.

\section{RESULTS AND DISCUSSION}

Total Income of the Family for a Month: The amount of money earned (Table1) by the family in a month, which was measured by recording total income of the family from all sources. Majority (41.75 per cent) of the Gaddi family were having monthly income between the ranges of Rs. 2000-4000. Only two per cent were having the monthly family income between the ranges of up to Rs. 1000 and above Rs. 8000. About 11.5 per cent families of Gaddi girls were having monthly income between the ranges of Rs. 1000-2000.

Heamoglobin content is measured for the degree of aneamia present in adolescent girls. Heamoglobin levels shows the prevalent of iron deficiency among gaddi girls.It has been observed from table 2 that 16.5 per cent Gaddi girls with 10-12 g/dl haemoglobin levels. $11.5 \%$ of girls were in the severe category of haemoglobin level i.e. less than 7. Most of the

Table 1: Monthly family income of adolescent Gaddi girls

\begin{tabular}{lcc}
\hline Family Income $($ Rs. $)$ & No. of girls & Per cent \\
\hline Up to 1000 & 8 & 2.0 \\
$1000-2000$ & 46 & 11.5 \\
$2000-4000$ & 167 & 41.75 \\
$4000-6000$ & 143 & 35.75 \\
6000-8000 & 28 & 7.0 \\
Above 8000 & 8 & 2.0 \\
\hline
\end{tabular}

girls 72 per cent were having 7-10 g/dl of haemoglobin level. There is no single girls of Gaddi tribe whose haemoglobin level was normal indicated iron deficiency. Jaishree et al (1996) was also reported that the basis of haemoglobin content in the blood on 265 adolscent girls were found mild to moderate degree of anaemic. Magyla and Jaya (1996) found that there were cases of severe malnutrition among tribal children (7-14 years). It has been shown from the results that most of the gaddi girls were suffering from aneamia it means their diet was deficient in iron rich food like green leafy vegetables jaggery, legumes etc.

Table 2: Haemoglobin level of adolescent Gaddi girls

\begin{tabular}{llr}
\hline Heamoglobin level $(\mathrm{g} / \mathrm{dl})$ & Categories & Per cent \\
\hline Less than 7 & Severe & 11.5 \\
$7-10$ & Moderate & 72.0 \\
$10-12$ & Mild & 16.5 \\
Greater than 12 & Normal & - \\
\hline
\end{tabular}

Body mass index indicated the relative fatness. It is calculated from height and weight of the respondents. BMI is classified into six categories, starting from the lowest i.e. $<16.0$ and height i.e. 25.0-30.0. Table 3 shows body mass index of adolescent girls. Most of the girls, 22.25 per cent were suffering from chronic energy deficiency grade III, 19.75 per cent and 17.5 per cent were showing low weight but normal and chronic energy deficiency grade II respectively. Only 0.25 per cent gaddi girls were having body mass index obese grade I. Anonymous (1989) reported that most of the girls were in chronic energy deficiency gaddi II and I. Gaddi girls suffered from chronic energy deficiency Grade III, Grade II and Grade I due to less intake of energy rich foods like ghee, butter, oil, sugar and more expenditure of energy in

Table 3: Body mass index of adolescent Gaddi girls

\begin{tabular}{lll}
\hline $\begin{array}{l}\text { BMI } \\
\text { class }\end{array}$ & $\begin{array}{l}\text { Prerumption } \\
\text { diagnosis }\end{array}$ & Percent \\
\hline$<16.0$ & CED grade III & 22.25 \\
$16.0-17.0$ & CED grade II & 17.5 \\
$17.0-18.5$ & CED grade I & 21.5 \\
$18.5-20.0$ & Low weight-normal & 18.75 \\
$20.0-25.0$ & Normal & 19.75 \\
$25.0-30.0$ & Obese Grade I & 0.25 \\
\hline CED-Chronic energy deficiency
\end{tabular}


heavy work loads than consumed. A result shows that most of the girls were suffering from the chronic energy deficiency grade III. It means the height and weight of the girls were lower according to their age and they were deficient in most of the energy rich foods.

Family income is important factor for influencing dietary practices and food intake of the family. Table 4 presents the relation between income of the family and BMI of respondents. As depicted in table that as the income increased, the BMI was also increased. The prevalence of malnutrition among lower income groups was high as compared higher income groups. Maximum 67.14 per cent gaddi girls were suffering from chronic energy deficiency grade I, followed by 57.35 per cent were low weight and were falling in income ranged between Rs. 2001-4000 and 4001-6000, respectively. While, 25.04 per cent girls were suffering from high degree of malnutrition, were in the income group of Rs. 1001-2000. No single respondent was normal in the income group of up to 1000 and 1001-2000. Chi-square value shows the significant association between income of the family and body mass index. It showed that malnutrition was prevalent among lower income group. In higher income group families of gaddi tribe were afford the energy rich food and able to buy from the market, also they were more aware about the diseases related to deficient diet.

Association between family income of respondents and haemoglobin level was presented in table 5. Most of the gaddi girls 43.48 per cent were falling in sever degree of anemia i.e. the level of heamoglobin was less than $7 \mathrm{~g}$.dl, belonging to family income ranges between Rs 2001-4000, followed by 26.07 per cent were belonging to the family income of Rs 1001-2000. About 47 per cent girls were falling in moderate and mild degree of heamoglobin level was belonging to family income ranges between Rs 2001-4000 and 4001-6000 respectively. The chi-square calculated showed significant association between family income and anemia among girls.

It has been seen from the result that iron deficiency was prevalent less in the higher income group than the lower income group. In higher income group women girls were more aware about the iron deficiency. Therefore, they were consume iron rich food.

Table 4: Association between family income and body mass index of Gaddi girls.

\begin{tabular}{|c|c|c|c|c|c|c|c|c|}
\hline \multirow[t]{2}{*}{ Income (Rs.) } & \multicolumn{6}{|c|}{ BMI Class } & \multirow{2}{*}{\multicolumn{2}{|c|}{ Total }} \\
\hline & $>16.0$ & $16.0-17.0$ & $17.0-18.5$ & $18.5-20.0$ & $20.0-25.0$ & $25.0-30.0$ & & \\
\hline Upto 1000 & $6 \quad(6.74)$ & $2 \quad(2.86)$ & - & - & - & - & 8 & $(2.0)$ \\
\hline $1001-2000$ & $23(25.0)$ & $11(15.79)$ & $12(13.9)$ & - & - & - & 46 & (11.5) \\
\hline $2001-4000$ & $41(46.0)$ & $47(67.14)$ & $25(29.0)$ & $24(32.0)$ & $30(37.8)$ & - & 167 & (41.75) \\
\hline $4001-6000$ & $18(20.2)$ & $10(14.29)$ & $40(46.5)$ & $43(57.35)$ & $32(40.5)$ & - & 143 & $(35.75)$ \\
\hline $6001-8000$ & $1 \quad(1.12)$ & - & $9(10.4)$ & $7 \quad(9.3)$ & $11(13.93)$ & - & 28 & (7.0) \\
\hline Above 8001 & - & - & - & $(1.35)$ & $\begin{array}{ll}6 & (7.59) \\
\end{array}$ & $1(10.0)$ & 8 & $(2.0)$ \\
\hline Total & $89(22.2)$ & $70(17.5)$ & $86(21.5)$ & $75(18.75)$ & $79(19.75)$ & $1(0.25)$ & 400 & (10.0) \\
\hline
\end{tabular}

Figures in parenthesis indicate percentage

$\chi^{2}$ cal $=98.06$ significant at $5 \%$ level.

Table 5: Association between family in come of respondents and haemoglobin level

\begin{tabular}{|c|c|c|c|c|c|c|c|}
\hline \multirow{3}{*}{$\begin{array}{l}\text { Income } \\
\text { Upto } 1000\end{array}$} & \multicolumn{7}{|c|}{ Haemoglobin level } \\
\hline & Severe & \multicolumn{2}{|c|}{ Moderate } & Mild & \multirow{2}{*}{$\frac{\text { Normal }}{-}$} & \multicolumn{2}{|c|}{ Total } \\
\hline & $5(10.87)$ & 2 & $(0.69)$ & $1 \quad(1.51)$ & & 8 & $(2.0)$ \\
\hline $1001-2000$ & $12(26.07)$ & 29 & $(10.06)$ & $5 \quad(7.58)$ & - & 46 & $(11.5)$ \\
\hline $2001-4000$ & $20(43.48)$ & 137 & (47.07) & $10(15.15)$ & - & 167 & $(41.75)$ \\
\hline $4001-6000$ & $6(13.05)$ & 106 & $(36.80)$ & $31(46.97)$ & - & 143 & $(35.75)$ \\
\hline $6001-8000$ & $3 \quad(6.53)$ & 13 & (4.54) & $12(18.18)$ & - & 28 & $(7.0)$ \\
\hline Above 8000 & - & 1 & $(0.34)$ & $7(10.7)$ & - & 8 & $(2.0)$ \\
\hline Total & $46(11.5)$ & 288 & $(72)$ & $66(16.5)$ & - & 400 & $(100.0)$ \\
\hline
\end{tabular}

Figures in parenthesis indicate percentage

$\chi^{2}$ cal $=79.27$ significant at $5 \%$ level. 


\section{CONCLUSION}

It can be concluded from the study that adolescent girls belonging to the gaddi tribe of Himachal Pradesh was suffering from malnutrition and anemia. Most of the girls were malnourished. Family income had great influence on the dietary habit of the respondents. Malnutrition was prevalent among girls belonging to lower income groups. The main cause of malnutrition, under weight and aneamia was inadequate intake of energy rich foods green leafy vegetable, legumes and also lack of awareness and knowledge regarding dietary practices in adolescent age.

\section{REFERENCES}

Anonymous. 1989. "Growth of Affuelent Indian Girls During Adolescence", in Nutrition Foundation of India. Scientific Report 10. ICAR, New Delhi.

Gupta, D. and Monica. 1987. "Selective discrimination against female children in rural Punjab." Indian Population and Development Review, 13: 77-100.

Jaishree, P.J., R. N. Snehalata and M. N. Vijaya. 1996. "Prevalence of Anaemia among school going adolescent Girls of Parbhani." Ind. J. Nut. Diet., 36: 268-274.

Mayla, P.S. and N. Jaya. 1996. "Prevalence of malnutrition among tribal children." Ind J. Nut Diet., 34: 214-220.

Mohan, J. 2002. The Wonderland of Himachal PradeshAn Encyclopedia. New Delhi: H.G. Publication. 